\title{
O PAPEL DA LITERATURA NO EXERCÍCIO DO DIREITO ENQUANTO PRÁTICA INTERPRETATIVA
}

\begin{abstract}
Aline Mariane Ladeia Silva ${ }^{1}$
Resumo: O presente ensaio tem como objetivo analisar os vieses interpretativos do Direito. Para tanto, apresenta uma abordagem sobre o positivismo jurídico, objetivando compreender a discricionariedade como um de seus elementos, a fim de expor os conceitos de jurisdição e constitucionalismo para auxiliar na problematização do positivismo como uma teoria perigosa para o Estado Democrático de Direito. Em sequência, elucida-se o movimento denominado giro-linguístico para contextualizar as concepções do direito enquanto prática interpretativa propostas por Ronald Dworkin e alcançar o conceito de verossimilhança como objeto finalístico das narrativas processuais.
\end{abstract}

Palavras-chave: Hermenêutica; Interpretação; Literatura; Teoria narrativista; Verossimilhança.

\section{THE ROLE OF LITERATURE IN THE EXERCISE OF LAW AS AN INTERPRETATIVE PRACTICE}

\begin{abstract}
The present essay will analyze the interpretative biases of Law. To this end, it presents an approach on legal positivism, aiming to understand discretion as one of its elements and to present of concepts of jurisdiction and constitutionalism to positivity problems as a dangerous theory for the Democratic Rule of Law. Subsequently, it approaches a movement called linguistic turn to contextualiz the conceptions of law as an interpretative practice proposed by Ronald Dworkin and to start the discussion about the concept of verisimilitude as a finalistic object of the procedural narratives.
\end{abstract}

Keywords: Hermeneutics; Interpretation; Literature; narrative theory; Verissimilitude.

\section{INTRODUÇÃO}

Sob influência dos mais variados resumos e manuais de direito "esquematizado", o consumo de verdades inquestionadas na prática do Direito tem gerado uma crise operada pelo senso comum do jurista. Essa roupagem em muito traduz o ensino jurídico dogmático que se vem praticando no Brasil.

\footnotetext{
1 Mestranda em Direito pelo Programa de Pós-Graduação Strictu Sensu do Centro Universitário FG - UniFG. Pesquisadora bolsista da Fundação de Amparo à Pesquisa do Estado da Bahia - FAPESB. Pesquisadora do Grupo de Pesquisa Cultura, Arte, Direito, Informação e Sociedade - CADIS. Pesquisadora do Núcleo de Estudos em Direito e Literatura - SerTão.
} 
Nos últimos anos, as notícias de corrupção envolvendo o poder legislativo e executivo ganharam lugar nos noticiários. No imaginário popular, o judiciário passa a ser, então, tábua de salvação da democracia e desfruta de um protagonismo sem precedentes. Contudo, o que se observa é que nem sempre as decisões são acertadas e/ou nem sempre essas decisões possuem coerência com os preceitos constitucionais fundamentais.

É nesse contexto que o ensino multidisciplinar no direito, aliado à hermenêutica, entra em cena para auxiliar no processo de compreensão dos novos arranjos que deram origem aos problemas envolvendo a jurisdição brasileira, propondo uma problematização filosófica, hermenêutica, literária etc.

Se a prática do Direito, conforme leciona Dworkin (2014, p. 272), é uma prática interpretativa que leva em consideração os princípios de justiça, equanimidade ${ }^{2}$ e devido processo legal, de forma que "a história jurídica seja coerente com o presente e o futuro" (CHUEIRI, 2019, p. 56), a literatura é o melhor instrumento para auxiliar nessa prática. Desse modo, partindo da relação entre Direito e Literatura, o presente trabalho se propõe a analisar de que forma a literatura pode ser útil no pensamento e nas práticas jurídicas.

Para tanto, primeiramente, fará abordagem conceitual do positivismo jurídico, objetivando compreender a discricionariedade como um de seus elementos, adentando na concepção de vontade do juiz. No segundo momento, serão oferecidos os conceitos de jurisdição e de vontade da lei, a fim de auxiliar na problematização do positivismo como uma teoria perigosa para o Estado democrático de Direito. Posteriormente, faz-se a uma abordagem desde o surgimento constitucionalismo até o que se compreende por força normativa da constituição. Em seguida, apresenta-se a relevância do giro-linguítico para o desenvolvimento da teoria interpretativista de Ronald Dworkin para, por fim, alcançar a verossimilhança como objeto finalístico das narrativas processuais.

\section{O POSITIVISMO E A VONTADE DO JUIZ}

Entre o século XVIII e XIX, no período que compreendia o fim da idade média e início da idade moderna, o positivismo jurídico surge como a escola doutrinária hegemônica. Após a derrocada do regime absolutista, a soberania popular buscava impor limites aos

\footnotetext{
${ }^{2}$ Pedron et al. (2019, p. 81) Informa que essa expressão é a mais apropriada para traduzir o termo "fairness".
} 
alvedrios monárquicos, razão pela qual surge a necessidade de limitar o poder concentrado e ilimitado do soberano (FERNANDES; BICALHO, 2011).

O povo passou a ter titularidade do poder, cujo exercício foi conferido aos seus representantes legitimados a expressar a vontade popular por meio da instrumentalidade da lei (FERNANDES; BICALHO, 2011), conforme se registrou por meio da Declaração de Direitos do Homem e do Cidadão:

Art. $6^{\circ}$. A lei é a expressão da vontade geral. Todos os cidadãos têm o direito de concorrer, pessoalmente ou através de mandatários, para a sua formação. Ela deve ser a mesma para todos, seja para proteger, seja para punir. Todos os cidadãos são iguais a seus olhos e igualmente admissíveis a todas as dignidades, lugares e empregos públicos, segundo a sua capacidade e sem outra distinção que não seja a das suas virtudes e dos seus talentos (FRANÇA, 1973).

Desse modo, os movimentos constitucionais modernos, ganham força e são acompanhados de um mito no sistema jurídico: a lei (FERNANDES; BICALHO, 2011).

O raciocínio positivista é de que a lei deveria ser aplicada de forma mecânica. Todavia, a lei editada no passado não seria suficiente para regular conflitos futuros e, considerando que a regra é, por "essência”, incompleta (STRECK, 2017, p. 47), nos casos difíceis (hard cases), em que há a ocorrência de anomias, não havia possibilidade de aplicação por subsunção, pelo simples fato de não existir norma que regulasse os referidos hard cases.

Assim, o pensamento jurídico objetivo desconsiderava o conteúdo da norma e reduzia a validade da lei à observância do procedimento estabelecido para a sua criação, tempo em que a atividade jurisdicional se restringia à aplicação mecânica das normas jurídicas.

Desse modo, visando a suprir a ineficiência apresentada pela aplicação exclusiva da lei, o positivismo lança mão da discricionariedade como saída para as omissões legislativas. Entretanto, essa alternativa possibilitou aos juízes se utilizarem da vontade como ferramenta do processo decisório:

Assim, da escola do direito livre, passando pela jurisprudência dos interesses, pelo normativismo kelseniano, pelo positivismo moderado de Hart, pelo positivismo póshartiano até chegar aos autores argumentativistas, como Alexy, há um elemento comum: o fato de que, no momento da decisão, sempre acaba sobrando um espaço 
que, necessariamente, será preenchido pela vontade discricionária do intérprete/juiz (não podemos esquecer que, nesse contexto, vontade e discricionariedade são faces da mesma moeda) (STRECK, 2017, p. 53).

Ao se resgatar o histórico do nazismo, na Alemanha, ou do fascismo, na Itália, percebe-se, ainda, que o modelo positivista foi amplamente utilizado como instrumento de legitimação daqueles que estavam no poder, muitas vezes como ferramenta de injustiça. Assim, nas palavras de Marinoni et al. (2016, p. 35):

\begin{abstract}
Isso significa que o positivismo jurídico, originalmente concebido para manter a ideologia do Estado liberal, transforou-se, ele mesmo, em ideologia. Nessa dimensão, passou a constituir a bandeira dos defensores do status quo ou dos interessados em manter a situação consolidada pela lei. Isso permitiu que a sociedade se desenvolvesse sob um asséptico e indiferente sistema legal ou mediante a proteção de uma lei que, sem tratar de modo adequado os desiguais, tornou os iguais em carne e osso mais desiguais ainda.
\end{abstract}

Percebe-se assim que, em se tratando de discricionariedade, qualquer decisão, ainda que injusta ou indevida, não pode ser considerada antijurídica (STRECK, 2017, p. 214), pelo simples fato de que a discricionariedade não impõe justificativa alguma, senão um juízo subjetivo e particular.

Segundo STRECK (2017, p. 73), Descartes inaugura o paradigma filosófico da filosofia da consciência. Isso porque, ao partir do raciocínio: penso, logo existo, utiliza-se de um método racional de base individualista, coloca o sujeito como centro de referência na busca da verdade e toda consciência acerca das coisas e do ente em sua totalidade acaba reportada à autoconsciência do sujeito humano, tido este como fundamento inabalável de toda certeza (STRECK, 2017, p. 73).

Desse modo, a filosofia da consciência é:

[...] caracterizada como aquisição e posse de conhecimento pelo sujeito, configurando-se agora com a metafisica de Hegel (2006), como a "consideração pensante dos objetos", com o que "o espírito pensante através de representações [...] progride para o conhecimento pensante e o conceito (STRECK, 2017, p. 74).

A partir de Nietzsche, a razão deixa de ser o fundamento principal e cede espaço para o subjetivismo, traduzido na vontade de poder, pela qual "a verdade é a que o sujeito estabelecerá a partir de sua própria consciência" (STRECK, 2017, p. 75). Para ele, a interpretação não significa a 'busca de um sentido a serviço de um sentido simplesmente dado, mas a posição de sentido a serviço da "vontade de poder"' (GADAMER, 2002, p. 384). 
Contudo, a experiência histórica revela que a autorização da discricionariedade/vontade pelo julgador, nos casos difíceis, oportuniza subjetivismos que não devem ser tolerados num Estado democrático de Direito, sob pena de violação das garantias fundamentais como a imparcialidade, o contraditório, a ampla defesa etc.

\section{A FUNÇÃO JURISDICIONAL E A VONTADE DA LEI}

Jurisdição [do latim juris (direito) + dictio (dizer)] é o poder/dever sob monopólio do Estado de dizer o direito (THEODORO, 2015, s.p.). Nas palavras de Humberto Theodoro Júnior (2015, s.p.) a jurisdição é a função do Estado de declarar e realizar, de forma prática, a vontade da lei diante de uma situação jurídica controvertida. Portanto, o juiz, investido na função jurisdicional, é quem decide o mérito de acordo com o que lhe propõem as partes (art. 141 do $\mathrm{CPC} / 15)^{3}$.

Em que pese se tratar de uma função pública, a jurisdição atua dirimindo conflitos de natureza particular, na maior parte do tempo, razão pela qual, em função do princípio da inércia, diz-se que é exercida ex officio (THEODORO, 2015, s.p.). Os jurisdicionados submetem suas pretensões ao Estado em busca de uma justa solução do conflito. Ou seja, autorizam ao Estado que faça valer a decisão judicial em substituição à vontade das partes.

O Estado, detentor do poder cogente, através da figura do juiz, não só irá decidir de forma imparcial, com base na "vontade da lei”, como também irá impor o cumprimento das decisões judiciais. Todavia, leciona Humberto Theodoro (2015, s.p.):

Esclareça-se que, na concepção atual de jurisdição, quando se cogita da realização
da "vontade da lei" não se refere à simples reprodução da literalidade de algum
enunciado legal, mas à implementação da norma jurídica, na qual se traduz o direito
do caso concreto, cuja formulação pelo julgador haverá de levar sempre em conta a
superioridade hierárquica das garantias constitucionais bem como a visão
sistemática do ordenamento jurídico, os seus princípios gerais e os valores políticos
e sociais que lhe são caros. Portanto, revelar e concretizar a "vontade da lei" é
expressão que modernamente equivale a definir e realizar "o direito", em sua
inteireza.

Em sua literalidade, a expressão "vontade da lei” leva em consideração a vontade do legislador, o que não é a sua melhor interpretação. Isso porque o legislador atua na

\footnotetext{
3 “Art. 141. O juiz decidirá o mérito nos limites propostos pelas partes, sendo-lhe vedado conhecer de questões não suscitadas a cujo respeito a lei exige iniciativa da parte".
} 
perspectiva do passado e não tem o condão de prever o futuro, motivo pelo qual, obviamente, não poderia regulamentar fatos sociais posteriores no exercício da atividade legiferante ((MARINONONI; ARENHART; MITIDIERO, 2016, p. 107). A norma exigirá certo grau de transcendência interpretativa na sua aplicação, pois como explica Humberto Theodoro (2015, s.p.): "a ordem legal positiva aspira a ser exaustiva, mas não consegue exaurir toda necessidade normativa da sociedade".

Durante a percepção de que a norma positivada não é o bastante, surge a necessidade de elevar a interpretação a um nível científico que auxilie na condução de julgamentos justos, que garantam a efetividade das garantis constitucionais.

\section{O CONSTITUCIONALISMO E A FORÇA NORMATIVA DA CONSTITUIÇÃO}

O constitucionalismo, movimento que surge no mundo pós-bélico, insere a norma constitucional numa nova perspectiva, sob a qual passa a ter status de norma jurídica e suas disposições adquirem caráter vinculativo e obrigatório (BARROSO, 2005).

O modelo de Estado, por sua vez, agora intervencionista, além de resguardar direitos individuais, incumbe-se de conformar a ordem econômica e social a determinados postulados de justiça social (BARROSO, 2005).

Essas disposições normativas, indicadoras de fins sociais a serem alcançados, passaram a prever prestações estatais, de natureza positiva, cujo objetivo era atenuar desequilíbrios ocasionados pelo poder econômico e resguardar o bem comum (BARROSO, 2005).

A Constituição, dotada de superioridade jurídica em relação às demais normas integrantes do sistema, impôs que qualquer ato jurídico devia guardar conformidade com o seu conteúdo, sob pena de comprometimento da validade de sua existência (BARROSO, 1996, s.p). Além disso, inaugurou o caráter diretivo político das normas constitucionais, endereçadas, sobretudo, ao legislador (BARROSO, 1996, s.p).

Em função dos mencionados atributos conferidos à Carta maior, foi necessário criar uma forma de controle sistêmico que assegurasse a referida hierarquia normativa, razão pela qual foram desenvolvidos mecanismos que se convencionou chamar de "jurisdição constitucional" (BARROSO, 1996, s.p). 
Os referidos mecanismos possibilitaram a realização do controle de constitucionalidade, pela via judicial, com fito de fazer prevalecer o conteúdo contido na constituição (BARROSO, 1996, s.p). Assim, por meio da declaração de inconstitucionalidade, os atos normativos incompatíveis com aquele conteúdo seriam declarados inválidos e teriam a sua eficácia restringida (BARROSO, 1996, s.p).

Assim, a partir da década de 40, surge um novo modelo marcado pela supremacia da constituição, baseado na experiência americana, onde alguns países como Alemanha (1951) e Itália (1951) criam modelos próprios de controle de constitucionalidade, através da instituição de tribunais constitucionais, tendência adotada por boa parte da Europa (BARROSO, 2005).

No Brasil, a reconstitucionalização se inicia a partir da promulgação da Constituição de 1988, por meio da qual "[...] de maneira bem-sucedida, a travessia do Estado brasileiro de um regime autoritário, intolerante e, por vezes, violento para uma democracia" (FERNANDES; BICALHO, 2011).

É nessa conjuntura que a Constituição se torna centro do sistema jurídico, que passa a ser aberto, constituído de princípios e regras (BARROSO, 2005), “[...] onde desfruta não apenas da supremacia formal que sempre teve, mas também de uma supremacia material, axiológica” (BARROSO, 2005). Nesse sentido, Luiz Roberto Barroso afirma:

[...] a Constituição transforma-se no filtro através do qual se deve ler todo o direito
infraconstitucional. Esse fenômeno tem sido designado como constitucionalização
do Direito, uma verdadeira mudança de paradigma que deu novo sentido e alcance a
ramos tradicionais e autônomos do Direito, como o civil, o administrativo, o penal e
o processual (v. infra). Essa constitucionalização do Direito, potencializada por
algumas características associadas ao contexto filosófico do pós-positivismo -
centralidade da idéia de dignidade humana e dos direitos fundamentais,
desenvolvimento da nova hermenêutica, normatividade dos princípios, abertura do
sistema, teoria da argumentação -, tem tornado o debate jurídico atual extremamente
rico e instigante.

Como consequência do processo de constitucionalização do direito, os direitos fundamentais extrapolaram os limites da Constituição, ao passo que ao Estado foi conferido o dever de promovê-los e protegê-los, através da legitimação da jurisdição constitucional, cabendo o exercício do dever de proteção ao Judiciário.

Por conseguinte, tem-se como resultado a subordinação da lei aos direitos fundamentais, aos quais devem guardar conformidade, e a imunidade dos referidos direitos em relação ao processo político majoritário (BARROSO, 1996, s.p.). Assim, os mencionados 
direitos fundamentais materiais incidem de forma mediata sobre os particulares, por meio das decisões judiciais. Já os direitos fundamentais instrumentais regulam os processos estatais e sua eficácia direta e imediata (MARINONONI; ARENHART; MITIDIERO, 2016, p. 84).

Ao ser reconhecida a normatividade dos princípios constitucionais, como dignidade da pessoa humana, legalidade etc., oportunizou-se certa margem de discricionariedade ao intérprete (BARROSO, 1996, s.p), posto que "[...] a menor densidade jurídica de tais normas impede que delas se extraia, no seu relato abstrato a solução completa das questões sobre as quais incidem" (BARROSO, 1996, s.p).

Nesse aspecto, Luiz Guilherme Marinoni (2016, p. 210) leciona que "a conformação da lei ou da legislação faz com que o juiz de certo modo crie, mediante a interpretação ou controle da constitucionalidade, uma norma jurídica para justificar sua decisão.”

Superada a figura do "juiz boca da lei”, presente na teoria defendida por Chiovenda (1969, p. 80), na qual o julgador se obrigava à estrita aplicação da norma preexiste, ganha espaço a atuação do poder judiciário na prestação jurisdicional, onde a norma jurídica é reconstruída "a partir da interpretação de acordo com a Constituição, do controle de constitucionalidade e da adoção de postulados normativos para a harmonização dos direitos fundamentais no caso concreto" (MARINONONI; ARENHART; MITIDIERO, 2016, p. 110).

Ao juiz foi possibilitado compreender e atribuir sentido e valor aos novos casos concretos por meio da aplicação das leis, bem como da interpretação dos princípios constitucionais de justiça e pelos direitos fundamentais (MARINONONI; ARENHART; MITIDIERO, 2016, p. 102-103), devendo, para tanto, elaborar o raciocínio que leva à prestação da tutela jurisdicional por meio da interpretação. Tal atividade "não é meramente cognitiva, declaratória de uma norma preexistente, nem tampouco uma atividade que implique propriamente sua criação judicial, mas é uma atividade que colabora com a própria conformação da norma, outorgando significado ao seu texto" (MARINONONI; ARENHART; MITIDIERO, 2016, p. 109).

Nesse sentido, a evolução do sistema jurídico no Estado democrático de direito revela uma aparente solução para a celeuma dos "hard cases", através da negação de que a aplicação do direito não se resumiria à subsunção de um fato concreto a uma norma geral (KELSEN, 2002, p. 84). Contudo, o que se observa, de fato, é que tal solução esbarra com outro imbróglio: a discricionariedade nas decisões. 


\section{O GIRO-LINGUÍSTICO}

É cediço que a comunicação é uma atividade que se concretiza por meio da linguagem, todavia, em que pese seja o uso da linguagem universal e irrestrito, compreender o sentido da mensagem transmitida nem sempre é uma tarefa fácil, ainda mais quando se leva em consideração que as palavras possuem caráter polissêmico e, por isso, carregam consigo um elevado potencial de transmutação de sentido. Cada vez que são combinadas em ordens, conjuntos e contextos diversos transmitem mensagens distintas.

Conforme esclarece Ricoeur (1990, p. 19), a existência de contextos diversos impõe a atuação de uma atividade de discernimento pala qual se torna possível a produção de um sentido unívoco na recepção da mensagem e essa atividade de discernimento, ao reconhecer a mensagem unívoca a partir de palavras polissêmicas, é a função da interpretação.

Desse modo, os diferentes sentidos das palavras em contextos diversos fazem com que os textos escritos estejam muito mais suscetíveis a equívocos interpretativos e ambiguidades, pois não oportunizam o jogo de perguntas e respostas entre os interlocutores como ocorre durante um diálogo (RICOEUR, 1990, p.1 9). Por essa razão, o discurso escrito exige técnicas que suplantem os equívocos que venham a surgir em decorrência do processo de decodificação.

Diante dessa necessidade de interpretar univocamente os textos é que se observa a relevância da ciência hermenêutica identificada como "a teoria das operações da compreensão em sua relação com a interpretação dos textos" (RICOEUR, 1990, p. 19).

Durante o século XIX, Schleiermacher inicia a formação de uma ciência hermenêutica, com a finalidade de desenvolver um método para sanar mal entendidos (PEDRON; OMMATI, 2019, p. 120), já que para ele "todos os problemas de interpretação são, na realidade, problemas de compreensão" (GADAMER, 1997, p. 279-289).

Todavia, como elucida Trindade (2006, p. 59), o método seria um álibi sob o qual o intérprete da lei se exonera de toda responsabilidade ao decidir, uma vez que passa a dispor da possibilidade de atribuir ao legislador o ônus da injustiça decorrente da sentença proferida. Portanto, desde Herder, compreender se torna mais do que um procedimento metodológico a fim de identificar o sentido de algo (GADAMER, 2002, p. 397).

$\mathrm{Na}$ modernidade, com a ruptura com a filosofia da consciência, ocorre o giro linguístico e o "sujeito surge na linguagem e pela linguagem, a partir do que se pode dizer que 
o que morre é a subjetividade "assujeitadora" e não o sujeito da relação de objetos [...]" (STRECK, 2017, p. 86).

A partir da virada linguística, o sujeito deixa de ser concebido como o fundamento do conhecimento, posto que o mundo é pré-existente aos seus questionamentos (STRECK, 2017, p.87). Isso significa dizer que o sentido não mais se extrai da consciência, mas da linguagem e essa relação é o que determina a condição de possibilidade de estarmos no mundo (STRECK, 2017, p.87). Para tanto, Heidegger (apud GADAMER, p. 386) esclarece que "o ser que pode ser compreendido é linguagem".

Assim, a linguagem como algo pré-concebido deixa de ser um mero instrumento integrante da relação sujeito-objeto e passa a integrar uma universalidade de compreensão, na qual os sentidos se antecipam ao sujeito e são pré-existentes a qualquer concepção individual (STRECK, 2015, p. 16-17). Em outras palavras, percebeu-se que o sentido do mundo não surge da subjetividade (assujeitadora) do sujeito, mas a partir de uma estrutura prévia de compreensão universal, composta por um contexto de significâncias e significados que será chamado mundo (STRECK, 2015, p.18-19).

\subsection{O direito como uma prática interpretativa}

No livro Uma questão de princípio, Dworkin sustenta que a prática jurídica é uma questão de interpretação geral e propõe uma comparação da interpretação jurídica com outros tipos de interpretação, em especial a literária, a fim melhorar compreensão do Direito (DWORKIN, 2000, p. 217).

Ele acredita que o problema central da doutrina analítica diz respeito ao sentido que se deve dar às proposições de direito, vale dizer, no nexo que os juristas estabelecem para dizer o que é o direito com relação a uma certa questão. Assim, o autor passa à análise dos tipos de proposições e de que modo elas ocorrem, tempo em que lança mão de duas perguntas: "De que tratam as proposições jurídicas? O que podem torná-las verdadeiras ou falsas?" (DWORKIN, 2000, p. 218).

Para tanto, apresenta as seguintes proposições:

1) Proposições descritivas como sendo aquelas que acreditam os positivistas. Dizem respeito como as coisas são no direito e não como deveriam ser, pois são 
compreendidas como trechos da história e só podem ser verdadeiras, caso decorram de um evento legislativo (DWORKIN, 2000, p. 218);

2) Proposições controvertidas: expressam o que o falante quer que o direito seja. Seria uma tentativa de descrever algum direito objetivo puro ou natural, que existe em virtude da verdade moral objetiva e não da decisão histórica (DWORKIN, 2000, p. 218);

3) Preposições interpretativas da história jurídica: une elementos de descrição, somados a elementos de valoração (DWORKIN, 2000, p. 218).

Considerando tais esclarecimentos, a conclusão é de que as proposições descritivas não se sustentam em casos de anomia, diante da ausência de evento legislativo. As proposições controvertidas, por sua vez, não podem ser consideradas plausíveis, uma vez que expressam o que o falante prefere, sua política pessoal ou o que ele acredita ser objetivamente exigido pelos princípios de sua moralidade política (DWORKIN, 2000, p. 219).

As proposições de direito seriam, como melhor alternativa, interpretativas da história jurídica, onde a interpretação seria a técnica de análise jurídica. Técnica essa que não seria baseada na intenção dos autores (legislador/constituinte), mas sim em uma atividade interpretativa geral (DWORKIN, 2000, p. 220-221).

Desse modo, a interpretação como prática jurídica se daria como um modo de conhecimento, atentando para outros contextos dessa atividade, como na interpretação literária e outras formas de interpretação artística, uma vez que na literatura já foram defendidas muito mais teorias da interpretação do que no Direito, inclusive, teorias que contestam a distinção categórica entre descrição e valoração.

\subsection{A interpretação construtiva em Ronald Dworkin}

Em obra posterior, traduzida no Brasil com o título "O império do Direito", Dworkin desenvolve melhor sua tese sobre interpretação no que denomina de interpretação construtiva, dessa vez referindo-se à interpretação das práticas sociais.

A interpretação da prática social tem a finalidade de identificação do consenso comunitário sobre determinada prática e esse consenso deve ser forte o suficiente para justificar as afirmações interpretativas de outros participantes, ainda que haja a divergência entre eles (THEODORO FILHO, 2016, p. 665). 
A interpretação construtiva seria, portanto, sustentáculo para uma melhor interpretação da prática social na busca por uma resposta correta, posto que o julgador (intérprete) se voltaria para a atividade interpretativa, considerando aspectos do passado, presente e futuro. Por esse motivo, Dworkin argumenta que essa interpretação deve ser pautada em três etapas, quais sejam: pré-interpretativa, interpretativa e pós-interpretativa.

Num primeiro plano, deve haver uma etapa pré-interpretativa, "na qual são identificados as regras e os padrões que se consideram fornecer conteúdo experimental da prática" (DWORKIN, 2014, p.81). Nessa etapa, deve haver um grau de consenso forte e seria equivalente à identificação textual de espécies literárias como romances, peça etc (DWORKIN, 2014, p.81).

Já a fase interpretativa consiste naquela "em que o intérprete se concentre numa justificativa geral para os principais elementos da prática identificada na etapa préinterpretativa" (DWORKIN, 2014, p.81). Nesse momento, são oferecidas as fundamentações para a prática identificada na etapa anterior, de forma que o intérprete ofereça os argumentos suficientemente adequados para comprovar que está desenvolvendo, de fato, uma interpretação e não inovando como alguém que inventa uma nova prática. Desse modo:

\begin{abstract}
Assim como em relação às escolas críticoliterárias, cada uma dessas teorias normativas pretenderá identificar um propósito ou intenção geral, no qual a prática social se insere e pelo qual é justificada. Tal propósito, combinado com a articulação interpretativa proposta pela teoria normativa, será capaz de dar sentido à maior parte do conteúdo e da forma da prática social, de modo que esta, como um todo, ao ser justificada pelo propósito, também o promove. Haverá, obviamente, teorias normativas melhores e piores em decorrência do grau de explicação e de ajuste existente entre a teoria normativa e a prática social por ela explicada e justificada (THEODORO FILHO, 2016, p. 664).
\end{abstract}

Por derradeiro, tem-se a etapa pós-interpretativa, pela qual o intérprete realiza o "ajuste sua ideia daquilo que a prática "realmente" requer para melhor servir à justificativa que ele aceita na etapa interpretativa" (DWORKIN, 2014, p. 82). Seria ela, desse modo,

[...] um ajuste entre a teoria normativa elaborada na etapa interpretativa e a prática social identificada na etapa pré-interpretativa, tencionando, após a aplicação da teoria sobre a prática, justificar, repudiar ou estabelecer padrões de conduta vinculados à prática em questão (THEODORO FILHO, 2016, p.665). 
Destarte, a interpretação da prática social objetiva equilibrar a sua fundamentação (fase interpretativa) e as suas ressalvas/exigências pós-interpretativas (DWORKIN, 2014, p. 237).

\subsection{A verdade}

Considerando que o direito é uma ciência social complexa, Luiz Alberto Warat (1994, p. 14) denuncia o senso comum dos juristas. Para ele, os sentidos presentes no texto não se extraem da consciência ou da realidade, mas de um princípio de intertextualidade prédefinido pela sua própria história e esta, por sua vez, pelo diálogo conjunto de citações, sem origem identificada, que se repete e se alastra, em inúmeros contextos, e em interação com outros textos de uma cultura (2016, p. 14-15). A esse fenômeno Warat chama de "diálogo surdo".

Nessa perspectiva, o senso comum dos juristas seria toda informação reproduzida no âmbito jurídico como ideia inquestionável, como uma verdade pressuposta e consentida. Como exemplo, no âmbito direito, podemos mencionar a busca pela "verdade real".

A doutrina tradicional, durante muito tempo, condicionou a busca da verdade real como finalidade do direito para a resolução dos conflitos e a consequente pacificação social. Contudo, a realidade dos fatos pretéritos é um elemento difícil de ser capturado, posto que os fatos se perdem no tempo. Esse conceito de "verdade real" foi amplamente difundido, sem que se percebesse o quanto essa ideia é perigosa.

Warat (1994, p. 14) preleciona que a realidade é “o nome empregado no pensamento ocidental para o traçado polifônico das versões interpretativas". Gadamer (2002, p. 391), por sua vez, observa: "a interpretação é o que oferece a mediação nunca acabada e pronta entre homem e mundo e, nesse sentido a única imediatez verdadeira e o único dado real é o fato de compreendermos algo como algo". Do ponto de vista hermenêutico, texto é, portanto, uma realidade dada que resiste a encaixar-se numa expectativa de sentido, a partir de uma presunção primária de sentido (GADAMER, 2002, p. 393).

Em sequência, Gadamer (2002, p. 397) afirma que "a lei, enquanto estatuto ou constituição, necessita sempre da interpretação para a sua aplicação prática, o que significa, por outro lado, que toda aplicação prática implica interpretação". 
Todavia, o caráter interpretativo do Direito não dá margem à livre atribuição de sentido pelo intérprete. Ao contrário, Gadamer (2002, p. 397) esclarece que a linguagem escrita está exposta a abusos e a mal-entendidos e, por esse motivo, deve haver no próprio texto um horizonte de interpretação. Ou seja, o próprio texto se encarrega de limitar a "vontade de poder" daquele que o interpreta.

Desse modo, "seria, portanto, no âmbito da verossimilhança e da coerência narrativa - e não da verdade - que se devem fundar os critérios para conferir validade aos discursos presentes nas narrativas processuais" (TRINDADE; KARAM, 2019).

\title{
6 A TEORIA NARRATIVISTA DO DIREITO
}

Para a Teoria Narrativista do Direito, “o Direito possui natureza e propriedades narrativas" e se utiliza da literatura como dispositivo ficcional emancipador (CALVO, 2013, p. 50), posto que:

\begin{abstract}
Na ficcionalização dos fatos, o fático deixa de estar invertebrado, que foi quando esteve quando foi fato. Então os fatos são verdade, toda a verdade e nada mais que a verdade do que verossimilmente sucedeu. E então, de fato, essa verdade, como toda verdade, "tem uma estrutura de ficção"; e é porque - como descreve Lacan - o fíctício "não é em essência enganoso, mas falando estritamente, o que chamamos simbólico". "Toda verdade tem uma estrutura de ficção", repete Ricardo Piglia, para acrescentar que "as ficções são aparatos linguísticos que expõem indiretamente a verdade" (CALVO, 2013, p. 50).
\end{abstract}

A concepção do narrativa do Direito está inserida no estudo denominado Direito como Literatura, pelo qual se compreende que "todo processo judicial é uma narrativa que contém diversas narrativas" (TRINDADE, KARAM, 2019).

Diante da impossibilidade de se resgatar integralmente os fatos ocorridos no tempo passado, no que o senso comum dos juristas vem denominando de "verdade dos fatos", a verossimilhança apresenta uma perspectiva de aproximação factual, como uma espécie de reconstrução do momento pretérito através da narrativa processual.

Ronald Dworkin e Neil MacCormick foram os teóricos que obtiveram mais notoriedade no desenvolvimento da ideia de coerência narrativa (CALVO, 2013, p.48). Para Ronald Dworkin (2000, p.221), a utilização da literatura para o estudo do Direito é relevante, na medida em que a literatura se ocupa do estudo de teorias da interpretação da qual o Direito 
não se propõe. Assim, o autor esclarece que há diferença entre interpretar e modificar e que os princípios atuariam como agentes limitadores dessa interpretação.

Partindo dessa análise, numa de suas obras mais recentes denominada Justice for Hedgehogs, ele anuncia o conceito de hipótese estética pelo qual a interpretação de uma obra literária mostra de que maneira ler o texto revela-o como a melhor obra de arte, assim como deveria ocorrer no Direito, posto que o direito, por também ser uma prática interpretativa, deve ser lido da melhor forma (DWORKIN, 2000, p. 272).

A prática interpretativa não comporta modificações do texto interpretado, de modo que, para auxiliar nessa tarefa, há uma subteoria que parte da ideia de texto canônico (DWORKIN, 2000, p. 223). A ideia é a de que o próprio texto estipula uma restrição severa em nome de sua identidade, onde todas as palavras devem ser levadas em consideração e nenhuma pode ser mudada a fim de torná-lo uma obra de arte melhor (DWORKIN, 2000, p. 223).

Ainda se utilizando de conceitos literários, para ilustrar a sua teoria do direito como integridade, Dworkin apresenta a metáfora que denomina romance em cadeia. O romance seria escrito por vários autores (romancistas) que interpretam os capítulos já escritos da história para dar continuidade a ela, escrevendo novos capítulos da melhor forma para que, no fim, obtenham tanta qualidade quanto possível (DWORKIN, 2000, p. 276).

Nessa esteira, Gadamer (2002, p. 406) esclarece que o texto literário goza de um status especial, justamente porque apresenta uma função normativa que surge nele mesmo, não se referindo ao discurso originário nem à intenção do orador, mas possuindo sua própria autenticidade.

Recapitulando, pois, os conceitos já abordados, dentro da perspectiva atual e do complexo raciocínio que a ciência jurídica exige, pode-se inferir que o estudo na esfera do direito e literatura se apresenta como "promissor campo interdisciplinar que oferece novas possibilidades de compreensão tanto da natureza humana e dos conflitos sociais quanto dos impasses e desafios que o direito enfrenta na contemporaneidade" (KARAM, 2017). 


\section{CONCLUSÃO}

Ainda que a realidade possa ser reconstituída, através de inúmeros instrumentos probatórios que a legislação prevê $\hat{e}^{4}$, mesmo com o auxílio dos meios tecnológicos que a contemporaneidade oferece, o que se concretiza, pela via processual, são meras narrativas opostas pelos sujeitos que compõe a lide.

Desse modo, o processo seria formado por elementos discursivos que são assegurados às partes como desdobramento não só da garantia fundamental ao contraditório, como também ao princípio da isonomia (TRINDADE; KARAM, 2019).

No momento em que a verdade, após o giro linguístico, deixou de ser uma questão de método e passou a ser uma questão de interpretação, a literatura passou a desempenhar uma tarefa relevante para a melhor compreensão do Direito.

$\mathrm{Na}$ busca pela aproximação com a verdade, dada à impossibilidade de alcançá-la em sua completude, o Direito pode se espelhar na literatura, a fim de compreender os textos e as normas, a partir da melhor interpretação a lhes ser dada (hipótese estética), com a finalidade não só de superar as ambiguidades interpostas pela linguagem (STRECK, 2017, p. 34), mas também como condição de possibilidade para a construção de narrativas processuais que apresentem verossimilhança com os fatos.

Além disso, considerando que a jurisdição é uma atividade complexa, especialmente ao considerar a existência de casos difíceis ou não previstos em lei, o Direito deve se efetivar por meio de uma prática interpretativa séria e coerente com o ordenamento jurídico para oferecer aos jurisdicionados respostas plausíveis com o sistema jurídico em que estão inseridos, afastando-se, assim, o fantasma da discricionariedade judicial.

\section{REFERÊNCIAS}

BARROSO, Luís Roberto. O Direito constitucional e a efetividade de suas normas: limites e possibilidades da Constituição brasileira. 3. ed. Rio de Janeiro: Renovar, 1996, s.p.

\footnotetext{
${ }^{4}$ Conforme disposto no CPC/15: “Art. 369. As partes têm o direito de empregar todos os meios legais, bem como os moralmente legítimos, ainda que não especificados neste Código, para provar a verdade dos fatos em que se funda o pedido ou a defesa e influir eficazmente na convicção do juiz." Disponível em: http://www.planalto.gov.br/ccivil_03/_ato2015-2018/2015/lei/113105.htm Acesso em: 3 dez 2019.
} 
BRASIL. Novo Código de Processo Civil. Lei n. 13.105, de 16 de março de 2015. Institui o Código de Processo Civil. Diário Oficial da União, Brasília, DF, 16 mar. 2015. Disponível em: http://www.planalto.gov.br/ccivIl_03/_Ato2015-2018/2015/Lei/L13105.htm. Acesso em: 2 jan. 2020.

CHIOVENDA, Giusepe. Instituições de direito processual civil. v. 2. São Paulo: Saraiva, 1969.

DWORKIN, Ronald. O império do Direito. Jefferson Luiz Camargo. São Paulo: Martins Fontes, 2014.

DWORKIN, Ronald. Uma questão de princípio. Trad. Luís Carlos Borges. São Paulo: Martins Fontes, 2000.

FERNANDES, Ricardo Vieira de Carvalho. BICALHO, Guilherme Pereira Dolabella. Do positivismo ao pós-positivismo jurídico: o atual paradigma jusfilosófico constitucional. In Revista de informação legislativa, v. 48, n. 189, p. 105-131, jan./mar. 2011. Disponível em: Acesso em: 19 de Mai. de 2019, p. 106.

GONZÁLEZ, José Calvo. Direito Curvo. Trad. por André Karam Trindade, Luis Rosenfield, Dino del Pino. Porto Alegre: Livraria do Avogado, 2013.

KARAM, Henriete. Questões teóricas e metodológicas do direito na literatura: um percurso analítico-interpretativo a partir do conto Suje-se gordo!, de Machado de Assis. In Revista Direito Gv, 2017. Disponível em:

http://bibliotecadigital.fgv.br/ojs/index.php/revdireitogv/article/view/73327/70469 Acesso em: 22 jun. 2019.

MARINONI, Luiz Guilherme. ARENHARRT, Sérgio Cruz. MITIDIERO, Daniel. Novo curso de processo civil: teoria do processo civil, v.1, $2^{\mathrm{a}}$ ed. São Paulo: Revista dos Tribunais, 2016.

MARINONI, Luiz Guilherme. Novo Curso de processo civil: teoria do processo civil, volume 1 - 2. ed. rev., atual. e ampl. - São Paulo: Revistas dos Tribunais, 2016.

PEDRON, Flávio Quinaud; OMMATI, José Emílio Medauar. Teoria do direito contemporâneo: uma análise de teorias jurídicas de Robert Alexy, Ronald Dworkin, Jurgen Habermas, Klaus Gunther e Robert Brandom. Rio de Janeiro: Lumen Juris, 2019.

RICOEUR, Paul. Interpretação e Ideologias. Tradução: Hilton Japiassu. Rio de Janeiro: F. Alves, 1990.

STRECK, Lenio Luiz. Dicionário de Hermenêutica: Quarenta temas fundamentais da teoria do Direito à luz da Crítica Hermenêutica do Direito. Belo Horizonte: Casa do Direito, 2017.

STRECK, Lênio Luiz. O que é isto - decido conforme minha consciência? 5. Ed. Porto Alegre: Livraria do Advogado, 2015. 
THEODORO FILHO, Wilson Roberto. A teoria da interpretação em Ronald Dworkin. Revista Jurídica da Presidência. v.17, n.113, p.657-676, out. de 2015/jan. 2016, p.665. Disponível em: https://revistajuridica.presidencia.gov.br/index.php/saj/article/view/1176. Acesso em: 4 jan. 2020.

THEODORO JÚNIOR, Humberto. Curso de Direito Processual Civil - Teoria geral do Direito Processual Civil, processo de conhecimento e procedimento comum, v.1, 5. ed., Rio de Janeiro: Forense, 2015.

TRINDADE, André Karam; KARAM, Henriete. Polifonia e verdade nas narrativas processuais. Seqüência: Estudos Jurídicos e Políticos, Florianópolis, v. 39, n. 80, p. 51-74, jan. 2019. Disponível em: https://periodicos.ufsc.br/index.php/sequencia/article/view/21777055.2018v39n80p51. Acesso em: 22 jul. 2019.

TRINDADE, André Karam. A filosofia no direito: com Gadmer, contra Habermas, á procura de um paradigma de racionalidade através do qual seja possível pensar pós-metafisicamente a teoria do direito contemporâneo. Dissertação - Universidade do Vale do Rio do Sinos Unissinos. Brasil. 2006. Disponível em:

http://www.repositorio.jesuita.org.br/handle/UNISINOS/2379?show=full. Acesso em: 13 jan. 2020.

WARAT, Luis Alberto. Introdução Geral ao Direito. Interpretação da Lei: temas para uma reformulação. v.1. Porto Alegre: Sérgio Antônio Fabris Editor, 1994. 